\title{
Perception of flood and landslide risk in Italy: a preliminary analysis
}

\author{
P. Salvati, C. Bianchi, F. Fiorucci, P. Giostrella, I. Marchesini, and F. Guzzetti \\ CNR IRPI, via Madonna Alta 126, 06128 Perugia, Italy \\ Correspondence to: P. Salvati (p.salvati@irpi.cnr.it) \\ Received: 21 March 2014 - Published in Nat. Hazards Earth Syst. Sci. Discuss.: 15 May 2014 \\ Revised: - - Accepted: 7 August 2014 - Published: 29 September 2014
}

\begin{abstract}
Inundations and landslides are widespread phenomena in Italy, where they cause severe damage and pose a threat to the population. Little is known about the public perception of landslide and flood risk. This is surprising, as an accurate perception is important for the successful implementation of many risk reduction or adaptation strategies. In an attempt to address this gap, we have conducted two national surveys to measure the perception of landslide and flood risk amongst the population of Italy. The surveys were conducted in 2012 and 2013, and consisted of approximately 3100 computer-assisted telephone interviews for each survey. The samples of the interviewees were statistically representative for a national-scale quantitative assessment. The interviewees were asked questions designed to obtain information on (i) their perception of natural, environmental, and technological risks, (ii) direct experience or general knowledge of the occurrence of landslides and floods in their municipality, (iii) perception of the possible threat posed by landslides and floods to their safety, (iv) general knowledge on the number of victims affected by landslides or floods, and on (v) the factors that the interviewees considered important for controlling landslide and flood risks in Italy. The surveys revealed that the population of Italy fears technological risks more than natural risks. Of the natural risks, earthquakes were considered more dangerous than floods, landslides, and volcanic eruptions. Examination of the temporal and geographical distributions of the responses revealed that the occurrence of recent damaging events influenced risk perception locally, and that the perception persisted longer for earthquakes and decreased more rapidly for landslides and floods. We explain the difference by the diverse consequences of the risks. The interviewees considered inappropriate land management the main cause of landslide and food risk, followed by illegal construction, abandonment of the territory, and climate change. Comparison of the risk perception with actual
\end{abstract}

measures of landslide and flood risk, including the number of fatal events, the number of fatalities, and the mortality rates, revealed that in most of the Italian regions, the perception of the threat did not match the long-term risk posed to the population by landslides and floods. This outcome points to a need to foster an understanding of the public towards landslide and flood hazards and risks in Italy.

\section{Introduction}

Landslides and floods are recurrent and abundant phenomena in Italy, where they cause damage and pose a threat to the population (Guzzetti et al., 1994; Guzzetti and Tonelli, 2004). Landslide and flood hazards, and the associated risk, have been determined on various geographical scales in Italy, from the site-specific (local) to the synoptic (national) scale. On the local scale, detailed investigations have produced zonations of landslide and flood hazards and risks ("Piani di Assetto Idrogeologico"), which are used to design defensive structures and to implement mitigation strategies. On the synoptic scale, investigators have estimated the individual and collective risk posed by landslides and floods to the population (Guzzetti et al., 2005a; Salvati et al., 2010, 2012). Despite these efforts, little is known regarding the public perception of the risk posed by landslides and floods in Italy. This is surprising, because an appropriate perception of the risk is important for the successful implementation of risk reduction or adaptation strategies.

In an attempt to address this gap, in 2012 and 2013, we executed two national surveys to probe the perception of the population of Italy of landslide and flood risk. The two surveys were executed by conducting more than 3000 telephone interviews, and they provided sufficient information to perform a preliminary evaluation of the perception that 
the population has of landslide and flood risk and the geographical variations in Italy. In this paper, following a brief overview of concepts related to risk perception (Sect. 2), we describe the content of the two national surveys (Sect. 3). This is followed (Sect. 4) by a discussion of the results of the surveys, by a comparative analysis (Sect. 5) of the perception of landslide and flood risk with known levels of the two risks to the population, and by a discussion (Sect. 6) of our findings in the context of the literature on flood and landslide risk perception. We conclude (Sect. 7) by summarizing the lessons learnt.

\subsection{Glossary}

In this work, we use the term landslide for all types of mass movements, including debris flows and soil slips (Cruden and Varnes, 1996; Hungr et al., 2013), and we use the terms flood and inundation as synonyms for all events where water covers land not normally covered by water (directive 2007/60/EC, 2007). We use the term geo-hydrological hazards (risks) to encompass landslide and flood hazards (risks), and the term geophysical hazards to include earthquake and volcanic hazards (risks). In our work, technological hazards (risks) are human-induced hazards (risks).

\section{Background on risk perception}

Kasperson et al. (1988) have argued that the investigation of risk is at the same time a science and an expression of culture. During her/his life, an individual is exposed to various risks, some of which are voluntary (e.g. driving), whereas others are involuntary (Starr, 1969; Sunstein, 1997), or are not the direct result of a conscious choice made by the individual. Involuntary risks are associated typically with natural hazards, and others are generated, or intensified, by human actions or the lack of actions. Perception of risk depends on the subjective judgement and evaluation of an individual of a specific risk (Renn, 1992, 2004; Rohrmann and Renn, 2000). However, what one person perceives as potentially dangerous (i.e. risky), another person may consider safe (i.e. free of risk). The mental models and the psychological mechanisms that people use to judge, evaluate, tolerate, and react to risks are complex and modulated by culture and the social environments, and are conditioned and constantly revised by information obtained from multiple sources, including the media, and by the influence of peers and others (Morgan et al., 2001).

Research into risk perception attempts to understand the choices made by an individual, or a group of individuals, to judge, evaluate, tolerate, and react to risk (Fromm, 2005). However, the criteria adopted by individuals to judge and evaluate different risks, and to decide to accept (or not accept) a risk, vary, largely depending on multiple, general and local conditions and situations. Risk can be measured quantitatively, in terms of annual mortality (e.g. individual risk, Latter, 1969; Morgan, 1997; Cruden and Fell, 1997; WBGU, 1998; Jonkman et al., 2003), or by defining the probability that a damaging event may occur (e.g. societal risk; Fell and Hartford, 1997). Quantitative risk assessment is typical of the natural sciences. In Italy, Guzzetti (2000) and Guzzetti et al. (2005a) were the first to obtain quantitative estimates of landslide and flood risk to the population, and Salvati et al. $(2010,2012)$ have updated the estimates.

The social sciences typically investigate risk by adopting a framework that incorporates technical, psychological, societal, and cultural aspects (Schmidt, 2004). In this framework, multiple individual and social characteristics mould the perception of risk of an individual, or a group of individuals, and influence the way individuals and groups judge, evaluate, tolerate, and react to a risk. The individuals may add other factors in their understanding of a risk, including the known or perceived catastrophic potential of the risk, the impartiality and the controllability of the risk, the apparent or real voluntariness or involuntariness of the risk, and the known, inferred, or perceived short- and long-term effects and consequences of the risk (Slovich, 1987).

Risk scientists have proposed two general approaches to investigating risk perception. A first approach is based on the cultural theory developed in sociology and social anthropology (Douglas and Wildvsky, 1983; Wildavsky and Dake, 1990; Rippl, 2002). A second approach adopts the psychometric model developed in psychology and decision research (Fischhoff et al., 1978; Slovich, 1987). Cultural theory focuses on the concept that risk is a social construct, and that each social group has its own set of risks and criteria to judge, tolerate, and react to the risks. Based on these concepts, the theory categorizes individuals in groups based on broad cultural biases that can affect the perception of a risk. The groups include egalitarians, individualists, hierarchists, and fatalists (Marris et al., 1998; Tansey and O'Riordan, 1999). Conversely, the psychometric model, introduced in the 1970s (Fischhoff et al., 1978; Fromm, 2005), attempts to obtain cognitive maps of risk attitudes and perceptions (Slovic, 1987; Slovic et al., 1982), i.e. quantitative representations of the perception of the risk, using metrics, scalings, and statistics. In this context, the factors controlling risk perception are numerous, but the most relevant factors include (i) the fear of a risk, (ii) the number of people affected by a risk, and (iii) the fact that a risk is known or unknown. The psychometric paradigm can be used to explain how people judge a risk, and what the factors are that modulate the perception of a risk (Schmidt, 2004).

Multiple qualitative characteristics influence the perception of risk of an individual, or a group of individuals (Oltedal et al., 2004). These characteristics include voluntariness, controllability, distribution of risk and benefits, confidence in risk management, familiarity, personal experience, and the natural vs. human source of the risk. Perception of a risk is reduced when the risk is voluntary (chosen), and it 
is increased when the risk is imposed (Renn, 1992; Jungermann and Slovic, 1993). For risks that have the same or similar consequences, or similar probabilities of occurrence, a voluntary (chosen) risk is generally more acceptable than an involuntary (imposed) risk. This is because individuals associate a voluntary risk with an expected benefit that balances the consequences of the risk. Furthermore, individuals may believe (or are convinced) that they are able to control (and reduce) a voluntary risk and its consequences, regardless of whether this is possible or not, and risks perceived to be controllable are more acceptable that those perceived to be non-controllable. However, socio-psychological studies have shown that individuals tend to overestimate their ability to control a situation (a risk) (Sjöberg, 2000), resulting in an unrealistic optimism and the tendency to deny a risk (Weistein, 1980).

A risk perceived to be distributed fairly (impartially) in a group is more easily accepted than a risk perceived to be distributed unfairly (unequally) (Davy, 1996; Linnerooth-Bayer and Fitzgerald, 1996). In general, the least acceptable risks are those where the consequences are sustained by a group of people and a different group benefits from the (real or perceived) advantages. Also, risks perceived to be associated with a benefit are more easily accepted than risks perceived to have little or no benefit. In this perspective, the benefits serve as compensation for the risk.

Familiarity and habituation are additional factors that modulate risk perception. Familiarity indicates that an individual affected by a risk knows about the risk and its consequences. Habituation means that an individual is accustomed to a risk. A risk present for a long period is attenuated (i.e. perceived as more acceptable) due to habituation, even if the risk remains unchanged (Slovic et al., 1986). Familiarity and habituation explain why a known risk is better accepted than an unknown risk. Familiarity is influenced by time and uncertainty. Delayed effects tend to reduce familiarity, whereas immediate effects intensify familiarity. Familiarity is further affected by the uncertainty of being exposed, or not exposed, to a risk. Individuals that know they will be exposed to a risk become familiar with the risk more rapidly. Also, familiarity is more important for known than for unknown risks (Hazard and Seidel, 1993).

A difference exists in the perception of natural vs. human-induced (e.g. technological) risks (Rohrmann and Renn, 2000). Human-induced risks are usually more accepted than natural risks. In general, individuals are convinced that a risk posed by human actions (or a lack of actions) can be avoided or mitigated, e.g. by prudent behaviour, appropriate actions, or by improved knowledge about the risk. Conversely, risks posed by natural hazards (including the landslides and floods considered in this work) are less accepted. Individuals tend to perceive natural hazards as unavoidable, and believe that the consequences are largely independent of their abilities to cope with or to mitigate a risk.

\section{The surveys}

To evaluate the perception of natural risks in Italy, including landslide and flood risk, in collaboration with DOXA (www.doxa.it), a leading Italian company operating in the field of statistical research and opinion polls, we designed two surveys. For the surveys, we prepared two questionnaires designed to help the interviewees to consider first their general feelings about environmental and natural risks, and next, their specific understanding of landslide and flood risk. The number of questions in the questionnaires, and the number of interviews in our two surveys, were conditioned by the resources available to execute the polls.

The questionnaires consisted of five questions (Table 1), and were designed to obtain information on (i) the perception of natural, environmental, and technological risks, (ii) direct experience or general knowledge of the interviewees on the occurrence of landslides and floods in the areas where they lived (i.e. the municipality of residence, or the surrounding areas), (iii) the perception of the possible threat posed by landslides and floods to the personal safety of the interviewees, (iv) the general knowledge of the interviewees on the number of victims impacted by landslides or floods in the recent past, and (v) information on the natural and humaninduced causes that control landslide and flood hazards and risks in Italy. We modified slightly the questionnaire used for the second survey (in 2013), based on the results of the first survey (in 2012). More specifically, in the 2013 questionnaire, the question on the knowledge of the number of victims in the previous five years was replaced by a new question on the causes influencing landslide and flood occurrence (Table 1).

DOXA executed the two surveys using their Computer Assisted Telephone Interview (CATI) system. This is an interactive front-end computer system designed to help interviewers to ask questions over the phone, and to record and organize the responses (Ketola and Klockars, 1999). The system is capable of adjusting a pre-defined questionnaire based on the answers obtained and on information about the individual interviewees. To execute the two surveys, DOXA adopted their general-purpose "omnibus" sampling tool that selects statistically representative samples for quantitative research on the national scale (http://www.doxa.it/strumenti/doxabus/). The sampling strategy used a classification based on demographic variables, including (i) the size and distribution of the population in each Italian region (Table 2), (ii) sex by age, (iii) education, and (iv) occupation. The sampling strategy exploited a national database to select the interviewees randomly from a pool of 15000 Italian families. The pool of families was different for each of the two surveys.

The first survey was conducted in a 19-day period from 12 to 30 January 2012, and consisted of 3122 telephone interviews of individual adults, 15 years old or older. The second survey was executed in an 18-day period from 17 January to 3 February 2013, and consisted of 3126 telephone interviews 
Table 1. Questions listed in the questionnaires used to determine the perception of flood and landslide risk in Italy, in 2012 and 2013 . The original questions in Italian are in italics.

\begin{tabular}{|c|c|c|c|}
\hline 2012 & 2013 & & Question \\
\hline \multirow[t]{2}{*}{$*$} & \multirow[t]{2}{*}{$*$} & \multirow[t]{2}{*}{ Q1 } & $\begin{array}{l}\text { How much do you feel exposed to each of these risks: (a) landslide, (b) flood, (c) earthquake, (d) volcanic } \\
\text { eruption, (e) road accident, (f) environmental pollution? Possible answers: (1) considerably exposed, } \\
\text { (2) somewhat exposed, (3) little exposed, (4) not exposed. }\end{array}$ \\
\hline & & & $\begin{array}{l}\text { Quanto pensa di essere esposto a ciascuno di questi rischi: }(a) \text { frana, }(b) \text { inondazione, }(c) \text { terremoto, } \\
(d) \text { eruzione vulcanica, }(e) \text { incidente stradale, }(f) \text { inquinamento ambientale? Possibili risposte: }(1) \text { molto, } \\
\text { (2) abbastanza, (3) poco, (4) per niente. }\end{array}$ \\
\hline \multirow[t]{2}{*}{$*$} & \multirow[t]{2}{*}{$*$} & \multirow[t]{2}{*}{ Q2 } & $\begin{array}{l}\text { Among these natural events, (a) landslide, (b) flood, (c) earthquake, and (d) volcanic eruption, which } \\
\text { you believe to be most frequent or most likely to occur in the municipality where you live, or nearby? } \\
\text { Possible answers: (1) landslide, (2) flood, (3) earthquake, (4) volcanic eruption, (5) none of these, (6) } \\
\text { I don't know. }\end{array}$ \\
\hline & & & $\begin{array}{l}\text { Tra questi eventi naturali (a) frana, (b) inondazione, (c) terremoto, (d) eruzione vulcanica, quale crede } \\
\text { essere il più frequente o il più probabile che avvenga nel comune dove lei vive, o nelle vicinanze? Possibili } \\
\text { risposte: (1) frana, (2) inondazione, (3) terremoto, (4) eruzione vulcanica, (5) nessuno di questi, (6) non } \\
\text { so. }\end{array}$ \\
\hline \multirow[t]{2}{*}{$*$} & \multirow[t]{2}{*}{ * } & \multirow[t]{2}{*}{ Q3 } & $\begin{array}{l}\text { Do you have direct knowledge, because involved, or indirect information of a landslide or a flood that } \\
\text { occurred in the municipality where you live, or nearby? Possible answers: (1) yes, a landslide, (2) yes, a } \\
\text { flood, (3) yes, both, (4) no. }\end{array}$ \\
\hline & & & $\begin{array}{l}\text { Lei è venuto a conoscenza diretta, perché coinvolto, o indiretta, perché ne ha avuto notizia, di in una } \\
\text { frana o di un'alluvione avvenuta nel territorio comunale dove lei risiede, o nelle vicinanze? Possibili } \\
\text { risposte: (1) si, frana, (2) si, alluvione, (3) si, entrambe, (4) no, nessuna notiza. }\end{array}$ \\
\hline \multirow[t]{2}{*}{$*$} & \multirow[t]{2}{*}{$*$} & \multirow[t]{2}{*}{ Q4 } & $\begin{array}{l}\text { Do you think that geo-hydrological events such as landslides and floods can be a real threat to your } \\
\text { personal safety? Possible answers: (1) yes, (2) no. If yes, (1a) yes, a landslide, (1b) yes, a flood (one } \\
\text { option does not exclude the other). }\end{array}$ \\
\hline & & & $\begin{array}{l}\text { Lei ritiene che eventi idrogeologici quali le frane e le alluvioni possano essere una minaccia reale alla } \\
\text { sua incolumità personale? Possibili risposte: (1) si, (2) no. Se si, (1a) si, una frana, (1b) si, una alluvione } \\
\text { (sono possibili entranbe le opzioni). }\end{array}$ \\
\hline \multirow[t]{4}{*}{$*$} & & \multirow[t]{2}{*}{$\mathrm{Q}_{2012}$} & $\begin{array}{l}\text { Do you think that in the last five years in Italy, the number of victims of geo-hydrological events, includ- } \\
\text { ing landslides and floods, have been (1) between } 10 \text { and 100, (2) between } 100 \text { and 200, (3) between } 200 \\
\text { and } 400,(4) \text { more than } 400 \text {, or (5) I don't know. }\end{array}$ \\
\hline & & & $\begin{array}{l}\text { Lei ritiene che negli ultimi cinque anni in Italia le vittime causate da eventi idrogeologici quali le frane } \\
\text { e le alluvioni siano state: (1) tra } 10 \text { e } 100 \text {, (2) tra } 100 \text { e 200, (3) tra } 200 \text { e } 400 \text {, (4) oltre } 400 \text {, (5) non so. }\end{array}$ \\
\hline & \multirow[t]{2}{*}{ * } & \multirow[t]{2}{*}{$\mathrm{Q}_{2013}$} & $\begin{array}{l}\text { In your opinion, which of the following factors have the most influence in the occurrence of landslides } \\
\text { and floods: (a) inappropriate land management, (b) landscape characteristics, (c) abandoning the territory, } \\
\text { (d) illegal construction ("abusiveness"), (e) climate change, (f) I don't know. }\end{array}$ \\
\hline & & & $\begin{array}{l}\text { Secondo lei, quale tra i seguenti fattori influisce maggiormente nel verificarsi di frane ed alluvioni: }(a) \text { er- } \\
\text { rata gestione del territorio, }(b) \text { caratteristiche del territorio, }(c) \text { abbandono del territorio, }(d) \text { abusivismo } \\
\text { edilizio, }(e) \text { cambiamenti climatici, }(f) \text { non so. }\end{array}$ \\
\hline
\end{tabular}

The * symbol indicates the questions posed in 2012 and 2013.

of adults, 15 years old or older. The size of the samples (approx. 3100 interviews) allowed for the segmentation of the analysis on the regional scale. For this purpose, in each region, the number of interviews was proportional to the number of residents in the region (Table 2). For the Valle d'Aosta and the Trentino-Alto Adige regions, a specific oversampling strategy was adopted to guarantee statistically signif- icant results. For the Basilicata, Molise, and Umbria regions, the size of the samples was insufficient to obtain statistically significant results on the regional scale. DOXA estimated a sampling error of the results of $\pm 2 \%$, with a confidence level of $95 \%$.

We acknowledge that the two surveys are insufficient for determining temporal trends. However, the two surveys 
Table 2. Total number and percentage of telephone interviews performed in each region, for the 2012 and 2013 surveys. The right two columns give the total population (millions) and the percentage of the population in each region (source: Istituto Italiano di Statistica, ISTAT, http://www.istat.it).

\begin{tabular}{|c|c|c|c|c|c|c|c|}
\hline \multirow{3}{*}{ Region } & & \multicolumn{4}{|c|}{ Interviewees } & \multirow{2}{*}{\multicolumn{2}{|c|}{$\begin{array}{c}\text { Population } \\
2012\end{array}$}} \\
\hline & & \multicolumn{2}{|c|}{2012} & \multicolumn{2}{|c|}{2013} & & \\
\hline & & $\#$ & $\%$ & $\#$ & $\%$ & \# millions & $\%$ \\
\hline Piemonte & PIE & 230 & 7.4 & 200 & 6.4 & 4.358 & 7.3 \\
\hline Valle d'Aosta ${ }^{1}$ & VDA & 93 & 3.0 & 87 & 2.8 & 0.127 & 0.2 \\
\hline Lombardia & LOM & 496 & 15.9 & 514 & 16.4 & 9.701 & 16.3 \\
\hline Trentino-Alto Adige ${ }^{1}$ & TAA & 85 & 2.7 & 73 & 2.3 & 1.030 & 1.7 \\
\hline Veneto & VEN & 249 & 8.0 & 255 & 8.2 & 4.854 & 8.2 \\
\hline Friuli-Venezia Giulia & FVG & 63 & 2.0 & 77 & 2.5 & 1.218 & 2.1 \\
\hline Liguria & LIG & 77 & 2.5 & 86 & 2.8 & 1.567 & 2.6 \\
\hline Emilia-Romagna & EMR & 223 & 7.1 & 229 & 7.3 & 4.341 & 7.3 \\
\hline Toscana & TOS & 220 & 7.0 & 202 & 6.5 & 3.668 & 6.2 \\
\hline Umbria $^{2}$ & UMB & 49 & 1.6 & 49 & 1.6 & 0.883 & 1.5 \\
\hline Marche & MAR & 90 & 2.9 & 82 & 2.6 & 1.541 & 2.6 \\
\hline Lazio & LAZ & 226 & 7.2 & 275 & 8.8 & 5.500 & 9.3 \\
\hline Abruzzo & $\mathrm{ABR}$ & 60 & 1.9 & 68 & 2.2 & 1.306 & 2.2 \\
\hline Molise $^{2}$ & MOL & 25 & 0.8 & 21 & 0.7 & 0.313 & 0.5 \\
\hline Campania & CAM & 242 & 7.8 & 279 & 8.8 & 5.764 & 9.7 \\
\hline Puglia & PUG & 212 & 6.8 & 161 & 5.2 & 4.050 & 6.8 \\
\hline Basilicata $^{2}$ & BAS & 39 & 1.2 & 45 & 1.4 & 0.578 & 1.0 \\
\hline Calabria & CAL & 113 & 3.6 & 115 & 3.7 & 1.958 & 3.3 \\
\hline Sicilia & SIC & 259 & 8.3 & 236 & 7.5 & 5.000 & 8.4 \\
\hline Sardegna & SAR & 71 & 2.3 & 72 & 2.3 & 1.638 & 2.8 \\
\hline Italy & & 3122 & 100 & 3126 & 100 & 59.394 & 100 \\
\hline
\end{tabular}

collectively extend the size of the population probed (a total of 6248 individuals), and the second (2013) survey can be used to evaluate if - and to what extent - recent harmful events have modified the perception of natural risks in Italy.

\section{Results of the surveys}

The first question (Q1 in Table 1) was formulated to rank the perception of the risks posed by natural hazards, including landslides, floods, earthquakes, and volcanic eruptions, against the perception of risks posed by road accidents and environmental pollution, two human-induced (technological) risks. Results are summarized in Fig. 1. In 2013, people in Italy felt more exposed to technological than natural risks, and specifically to environmental pollution $(67 \%$, including $31 \%$ of the interviewees that felt "considerably" exposed and $36 \%$ that felt "somewhat" exposed), followed by road accidents $(55 \%$, of which $19 \%$ "considerably" and $36 \%$ "somewhat" exposed). The ranking was the same in 2012, with the interviewees feeling slightly less exposed to environmental pollution $(65 \%$, of which $29 \%$ felt "considerably" and $36 \%$ "somewhat" exposed) and significantly more ex- posed to road accidents (65\%, of which $21 \%$ felt "considerably" and $44 \%$ "somewhat" exposed). For natural hazards, in 2013, the interviewees felt most exposed to earthquakes (45\%, of which $15 \%$ "considerably" and $30 \%$ "somewhat" exposed), followed by flooding ( $24 \%$, of which $7 \%$ "considerably" and $17 \%$ "somewhat" exposed), landslides (17\%, of which $5 \%$ "considerably" and $12 \%$ "somewhat" exposed), and volcanic eruptions (12\%, of which $5 \%$ "considerably" and $7 \%$ "somewhat" exposed).

The ranking for the natural hazards was the same in 2012, with slightly different percentages. A general increase in the number of interviewees that felt "considerably" exposed to natural hazards $(+3 \%$ for earthquakes, $+1 \%$ for landslides, $+1 \%$ for floods) was accompanied by a decrease in the total number of interviewees that felt exposed to landslide or flood risk (i.e. the sum of the responses with "considerably" and "somewhat" exposed). Compared to 2013, in 2012, the interviewees felt slightly less exposed to earthquakes (42\%, of which $12 \%$ "considerably" and $30 \%$ "somewhat" exposed), slightly more exposed to flooding ( $27 \%$, of which $6 \%$ "considerably" and $21 \%$ "somewhat" exposed) and landslides (18\%, of which $4 \%$ "considerably" and $14 \%$ "somewhat" 

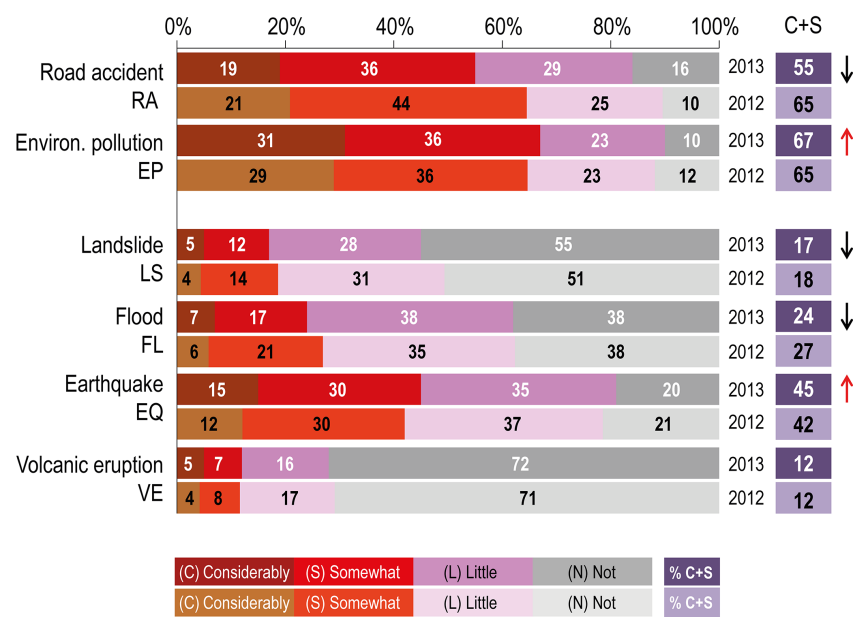

Figure 1. Answers to question 1 (Q1: How much you feel exposed to each of these risks: (a) landslide, (b) flood, (c) earthquake, (d) volcanic eruption, (e) road accident, (f) environmental pollution?), on the national scale, and for the 2012 and 2013 surveys. Horizontal bars show the percentage of interviewees that responded as being (C) "considerably", (S) "somewhat", (L) "little", or (N) "not" exposed to natural hazards, including landslides (LS), floods (FL), earthquakes (EQ), and volcanic eruptions (VE), to road accidents (RA), and to environmental pollution (EP). Black (red) arrows show a reduction (increase) in the percentages in 2013, compared to 2012. See Table 1 for the questions and the list of possible answers.

exposed), and equally exposed to volcanic eruptions (12\%, of which $4 \%$ "considerably" and $8 \%$ "somewhat" exposed). Considering the $2 \%$ sampling error, we conclude that the 2013 survey revealed a slight decrease in the perception of landslide and flood risk, and a slight increase in the perception of earthquake risk. The perception of volcanic risk remained the same.

In 2013, the interviewees felt most exposed to landslides in the Valle d'Aosta (39\% "considerably" and $17 \%$ "somewhat" exposed), which is a mountainous region, and in Calabria (16\% "considerably" and $26 \%$ "somewhat" exposed), which is a largely mountainous region, and most exposed to flooding in Liguria (21\% "considerably" and $28 \%$ "somewhat" exposed) and in Calabria (18\% "considerably" and $28 \%$ "somewhat" exposed). The regions with the smallest proportion of interviewees that felt exposed to landslides were Puglia (where most of the territory is flat) and Lombardia, and to floods were Trentino-Alto Adige and Lombardia (Fig. 2). The regions where the number of interviewees that felt increasingly "considerably" exposed to landslide risk in 2013 compared to 2012 were the Valle d'Aosta $(+33 \%)$, Sardegna $(+6 \%)$, Piemonte $(+5 \%)$, and Marche $(+3 \%)$. Similarly, the regions where the number of interviewees that felt increasingly "considerably" exposed to flood risk in 2013 were the Valle d'Aosta $(+9 \%)$, Abruzzo $(+7 \%)$, Calabria $(+7 \%)$, Sardegna $(+7 \%)$, and Lazio $(+3 \%)$.

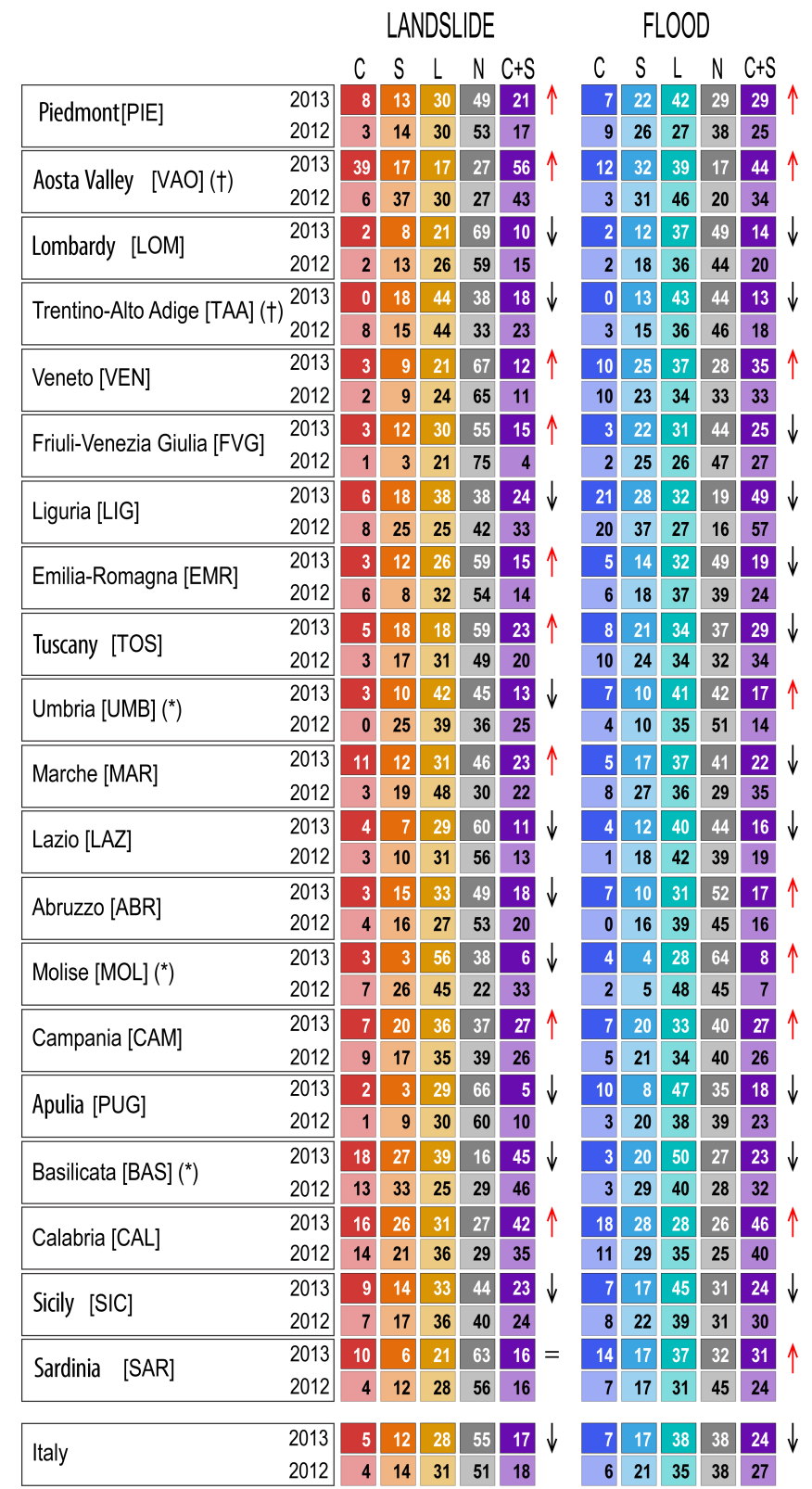

Figure 2. Answers to question 1 (Q1: How much you feel exposed to each of these risks: (a) landslide; (b) flood?), by region and for Italy, and for the 2012 and 2013 surveys. Colours show the percentage of interviewees that responded as being (C) "considerably", (S) "somewhat", (L) "little" or (N) "not" exposed to landslides or floods. The cumulated percentage of interviewees that responded as being "considerably" or "somewhat" exposed $(\mathrm{C}+\mathrm{S})$ is also given. Black (red) arrows show a reduction (increase) in the percentages in 2013, compared to 2012. A cross $(\dagger)$ marks regions where oversampling was performed to obtain statistically significant results. An asterisk $\left(^{*}\right)$ marks regions for which the number of interviews was insufficient to obtain statistically significant results. See Table 1 for the questions and the list of possible answers. 
The trend was different for earthquakes. The destructive seismic sequence in Emilia-Romagna, with a first earthquake on 20 May $2012\left(5.9 M_{\mathrm{L}}\right)$, a second earthquake on 29 May $2012\left(5.8 M_{\mathrm{L}}\right)$, and aftershocks exceeding $5.0 M_{\mathrm{L}}$ (Anzidei et al., 2012), conditioned the second (2013) survey. The earthquake caused 27 fatalities, at least 400 injured people, and up to 45000 homeless, and raised significantly the perception of earthquake risk in Emilia-Romagna, where $30 \%$ of the interviewees felt "considerably" exposed to earthquake risk, an increase of $19 \%$ compared to 2012. At the same time, the perception of landslide and flood risk decreased in the region. Interestingly, in 2013, the perception of earthquake risk increased in Abruzzo (26\% felt "considerably" exposed, $+15 \%)$, Calabria (33\%, +6\%), and Sicilia $(26 \%,+3 \%)$. Campania and Sicilia were the regions where the interviewees felt more exposed to volcanic risk $(25 \%$ felt "considerably" and $26 \%$ "somewhat" exposed in Campania, and $10 \%$ "considerably" and 20\% "somewhat" exposed in Sicilia). Campania and Sicilia have the most dangerous volcanic areas in Italy, i.e. the Vesuvius volcano and the Campi Flegrei in the greater Neapolitan area, in Campania, and the Etna volcano and the island of Vulcano, in Sicilia.

The second question (Q2 in Table 1) attempted to determine the ability of the interviewees to evaluate the frequency or the likelihood of occurrence of the different natural hazards, including landslides, floods, earthquakes, and volcanic eruptions, in the general area where they lived. Results are summarized in Fig. 3, which shows the results of both surveys, for the 20 regions and for the whole of Italy. On the national scale, earthquake was the natural hazard that, in 2013, the interviewees felt was more likely in their area $(41 \%)$, followed by flooding (30\%), landslides (10\%), and volcanic eruptions $(2 \%)$. The ranking was the same and the percentages were only slightly different in 2012 (39\% earthquakes, $31 \%$ floods, $9 \%$ landslides, and $4 \%$ volcanic eruptions). For both surveys, $15 \%$ of the interviewees felt that none of the listed hazards was likely or frequent in their area.

The interviewees considered earthquakes particularly likely in the Marche (69\% in 2013, $61 \%$ in 2012), Umbria $(60 \%, 68 \%)$, Basilicata $(64 \%, 63 \%)$, Abruzzo $(68 \%$, $57 \%)$, Molise $(62 \%, 51 \%)$, and Friuli-Venezia Giulia $(59 \%, 57 \%)$ regions (Fig. 3). These are the regions that have experienced severe earthquakes in the last decades (between 1976 and 2009), and that are considered at high or very high seismic risk (Boncio et al., 2004; Cucci et al., 1996). In the Emilia-Romagna region, northern Italy, the percentage of interviewees that considered an earthquake likely increased from $48 \%$ in 2012 - before the May-June 2012 seismic sequence (Anzidei et al., 2012) - to $73 \%$ in 2013. Calabria and Sicilia, in southern Italy, are areas where seismic risk is known to be high or very high (Slejko et al., 1998, http://zonesismiche.mi.ingv.it/), and where the proportion of interviewees that considered an earthquake likely was somewhat reduced (50\% in 2013 and $41 \%$ in 2012 in Calabria, $51 \%$ in 2013 and $47 \%$ in 2012 in Sicilia). The reasons

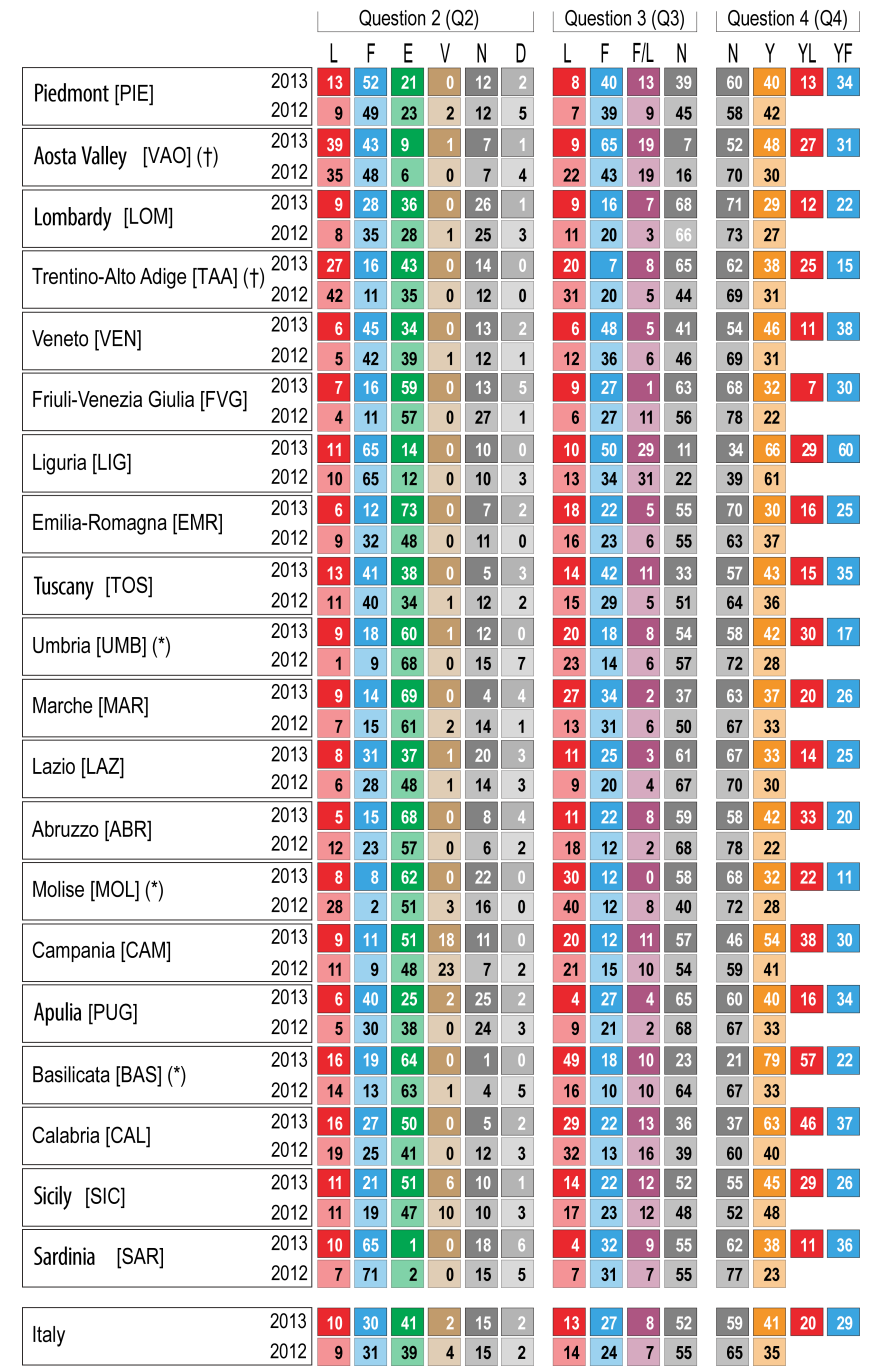

Figure 3. Answers to question $2(\mathrm{Q} 2$ : Among these natural events, (a) landslide, (b) flood, (c) earthquake, and (d) volcanic eruption, which you believe to be most frequent or most likely to occur in the municipality where you live, or nearby?), question 3 (Q3: Do you have direct knowledge, because involved, or indirect information on a landslide or a flood that occurred in the municipality where you live, or nearby?), and question 4 (Q4: Do you think that geohydrological events such as landslides and floods can be a real threat to your personal safety?), by region and for Italy, for the 2012 and the 2013 surveys. Colours show the percentage of the responses. Legend: L, landslide; F, flood; E, earthquake; V, volcanic eruption; N, None; D, I don't know; F/L, landslides and floods; Y, yes; N, no; YL, yes landslides; YF, yes floods. A cross ( $\dagger$ ) marks regions where oversampling was performed to guarantee statistically significant results. An asterisk (*) marks regions for which the number of interviews was insufficient to obtain statistically significant results. See Table 1 for the questions and the list of possible answers. 
for this outcome can be manifold, including the relatively long period without a destructive earthquake in the two regions. The last destructive earthquakes in the area were the 28 December 1908, 7.1 $M_{\mathrm{W}}$ Messina and Reggio Calabria earthquake and subsequent tsunamis, which killed more than 120000 people in northeastern Sicilia and southern Calabria, and the 14-15 January $1968,5.5 M_{\mathrm{W}}$ Belice earthquake in western Sicilia, which caused more than 300 fatalities (Boschi et al., 1995). On 9 September 1998, a 5.5 $M_{\mathrm{W}}$ earthquake hit Basilicata and the northern part of Calabria, causing moderate damage, and no fatalities. The regions where the least number of interviewees considered an earthquake likely were Sardegna $(1 \%, 2 \%)$ and the Valle d'Aosta $(9 \%$, $6 \%$ ). These regions are considered at low seismic risk in Italy (Slejko et al., 1998).

Inundations were considered frequent and likely by interviewees in Sardegna (65\% in 2013, $71 \%$ in 2012) and Liguria $(65 \%, 65 \%)$, followed by the Valle d'Aosta ( $43 \%$, $48 \%$ ), Veneto $(45 \%, 42 \%)$, and Toscana $(41 \%, 40 \%)$. Conversely, only a small proportion of the interviewees in Molise $(8 \%, 2 \%)$ considered an inundation likely. Landslides were deemed frequent and likely by interviewees in the Valle d'Aosta $(39 \%, 35 \%)$, Trentino-Alto Adige $(27 \%, 42 \%)$, and Calabria $(16 \%, 19 \%)$. Interestingly, in most of the regions, inundations were considered (much) more frequent and likely than landslides (Fig. 3). This is despite the fact that landslide fatalities and landslide mortality are larger than flood fatalities and flood mortality (Table 3). Volcanic activity was considered likely only by interviewees in Campania (18\% in 2013, $23 \%$ in 2012) and in Sicilia (10\%, 6\%). These are the two regions where volcanic risk is known to be high. Interestingly, a small number of interviewees considered a volcanic eruption likely even in municipalities located far away from any active volcano, and where volcanic risk is not present.

The third question (Q3 in Table 1) was specific to landslide and flood risk, and attempted to determine if the interviewees had direct experience or indirect knowledge of the occurrence of landslides or floods in the general area where they lived. Overall, in 2013, $27 \%$ of the interviewees were aware of an inundation (24\% in 2012) and $13 \%$ of a landslide (14\% in 2012) occurring in their municipality. Only $8 \%$ (7\% in 2012) of the interviewees responded that they were aware of both flood and landslide events in their municipality, or in the vicinity (Fig. 3). The result indicates that the majority of the interviewees (52\% in 2013, $55 \%$ in 2012) had no direct experience or indirect knowledge of landslide or flood events occurring in the area where they lived. This is in contrast to the large abundance and frequency of landslides and floods in Italy. Guzzetti et al. (1994) have identified more than 37000 sites affected by more than 61000 landslide or flood events in Italy in the 73-year period from 1918 to 1990 . All the Italian provinces have experienced recurrent landslides or floods, and of the total number of 8103 municipalities (in 1998), 6475 (79.9\%, $91 \%$ of the territory) have experienced at least one landslide or flood (Guzzetti and Tonelli, 2004). On the regional scale, the percentage of interviewees that were aware of an inundation in their municipality was largest in the Valle d'Aosta $(65 \%$ in 2013, $43 \%$ in 2012), followed by Liguria $(50 \%, 34 \%)$, Veneto $(48 \%$, $36 \%)$, Toscana $(42 \%, 29 \%)$, and Piemonte $(40 \%, 39 \%)$. Similarly, the percentage of the interviewees aware of a landslide occurring in their municipality was largest in Basilicata $(49 \%, 16 \%)$ and Molise $(30 \%, 40 \%)$, and large in Calabria (29\%, 32\%), Marche $(27 \%, 13 \%)$, Trentino-Alto Adige $(20 \%, 31 \%)$, Umbria $(20 \%, 23 \%)$, and Campania (20\%, $21 \%)$.

Inspection of Fig. 3 reveals that for some of the regions where there was an increase in the awareness of floods, there was a corresponding decrease in the awareness of landslides (i.e. the Valle d'Aosta, Liguria, Veneto, Abruzzo, and Calabria). The increased percentages for Toscana, Lazio, and Umbria may be the result of the serious flooding in November 2012 in central Italy that caused six fatalities and damage exceeding EUR 700 million. Similarly, the large increase for Liguria $(+16 \%)$ is probably a consequence of repeated flooding events in the autumn of 2012.

The fourth question (Q4 in Table 1) was designed to determine if the interviewees considered landslides and floods a threat to their personal safety. In 2012, the interviewees were given two possible choices, i.e. "yes", I consider landslides or floods a threat to my personal safety, or "no", I do not consider landslides or floods a threat to my personal safety. In 2013, the question was modified, so that when the response was "yes", the interviewees were asked to specify if they felt threatened by landslides, floods, or both; one option did not exclude the other.

In $2013,41 \%$ of the interviewees considered landslides and floods to be a threat to their personal safety (Fig. 3). The proportion was lower (35\%) in 2012. We explain the increase in the number of people that considered landslides and/or floods a personal threat in 2013 with the severe events that occurred in the period 2011-2012, which caused a total of 58 fatalities, 48 injuries, and more than 5000 homeless individuals (http://polaris.irpi.cnr.it/), and with the related coverage of the events by the media. On the regional scale, the percentage of the interviewees that considered landslides or floods a threat to their personal safety was largest in Liguria (66\% in 2013, $61 \%$ in 2012), followed by Calabria $(63 \%, 40 \%)$, Basilicata $(79 \%, 33 \%)$, Campania $(54 \%, 41 \%)$, Veneto $(46 \%, 31 \%)$, the Valle d'Aosta (48\%, $30 \%$ ), and Sicilia $(45 \%, 48 \%)$. In 12 of the 20 Italian regions, floods were perceived to be a greater threat than landslides. In some of these regions, the difference between the fear of floods and the fear of landslides exceeded $20 \%$, e.g. $31 \%$ in Liguria, $27 \%$ in Veneto, and $25 \%$ in Sardegna. Interviewees in southern Italy feared landslides more than floods, whereas in northern Italy, interviewees perceived flooding to be more dangerous than landslides (Fig. 3). Overall, Lombardia was the region where the interviewees perceived being 
Table 3. Total number of fatal events and fatalities caused by landslides and floods in the 20 Italian regions in the 50-year period 1964-2013. Average landslide and flood mortality rates in the period are also given.

\begin{tabular}{|c|c|c|c|c|c|c|c|}
\hline \multirow[t]{2}{*}{ Region } & & \multicolumn{3}{|c|}{ Landslides } & \multicolumn{3}{|c|}{ Floods } \\
\hline & & Events & Fatalities & Mortality & Events & Fatalities & Mortality \\
\hline Piemonte & PIE & 50 & 134 & 0.062 & 64 & 130 & 0.060 \\
\hline Valle d'Aosta & VDA & 12 & 25 & 0.423 & 4 & 5 & 0.085 \\
\hline Lombardia & LOM & 39 & 118 & 0.027 & 26 & 35 & 0.008 \\
\hline Trentino-Alto Adige & TAA & 50 & 351 & 0.800 & 26 & 32 & 0.077 \\
\hline Veneto & VEN & 24 & 71 & 0.034 & 21 & 25 & 0.012 \\
\hline Friuli-Venezia Giulia & FVG & 8 & 11 & 0.018 & 16 & 31 & 0.051 \\
\hline Liguria & LIG & 16 & 37 & 0.043 & 34 & 88 & 0.101 \\
\hline Emilia-Romagna & EMR & 2 & 49 & 0.025 & 11 & 15 & 0.008 \\
\hline Toscana & TOS & 28 & 64 & 0.039 & 49 & 88 & 0.051 \\
\hline Umbria & UMB & 8 & 15 & 0.038 & 9 & 14 & 0.035 \\
\hline Marche & MAR & 8 & 9 & 0.013 & 8 & 10 & 0.014 \\
\hline Lazio & LAZ & 15 & 24 & 0.010 & 14 & 27 & 0.011 \\
\hline Abruzzo & ABR & 6 & 8 & 0.013 & 3 & 5 & 0.008 \\
\hline Molise & MOL & 0 & 0 & 0.000 & 1 & 1 & 0.006 \\
\hline Campania & CAM & 87 & 293 & 0.106 & 22 & 29 & 0.011 \\
\hline Puglia & PUG & 6 & 12 & 0.006 & 15 & 30 & 0.016 \\
\hline Basilicata & BAS & 5 & 15 & 0.049 & 7 & 13 & 0.043 \\
\hline Calabria & CAL & 18 & 37 & 0.037 & 10 & 28 & 0.028 \\
\hline Sicilia & SIC & 20 & 67 & 0.027 & 66 & 130 & 0.054 \\
\hline Sardegna & SAR & 10 & 14 & 0.021 & 31 & 45 & 0.061 \\
\hline Italy & & 412 & 1354 & 0.089 & 437 & 781 & 0.037 \\
\hline
\end{tabular}

threatened least by landslides or floods. This is despite a history of damaging landslide and flood events in this region. In Lombardia, the last severe event occurred in November 2002, when landslides and floods caused severe damage to infrastructures and buildings; there were more than 7000 evacuees, and three people died due to landslides. The lack of highly damaging events in recent years can explain the reduced perception of the threat. The geographical distribution of the population in the region, which is concentrated in urban and suburban areas, also contributes to the reduced perception of the threat.

Sex and age little modified the perception of being threatened by a landslide or a flood (Fig. 4). In 2013, women (42\%) felt more threatened than men (40\%). The percentages were different in 2012, when women (33\%) felt less threatened than men (38\%). In 2013, $45 \%$ of the young interviewees ( 34 years old or younger) felt threatened by landslides or floods. The percentage decreased to $42 \%$ for adults ( 35 to 54 years old), and to $37 \%$ for seniors (55 years old or older). The percentages changed in 2012 , but the relative proportions remained the same, with $41 \%$ of the young interviewees, $40 \%$ of adults, and $27 \%$ of seniors feeling threatened by landslides or floods. The latter result may be conditioned by familiarity and habituation, and the knowledge of the risks (Slovic et al., 1986; Hazard and Seidel, 1993).

The fifth question was different in 2012 and 2013 (Table 1). In 2012, the interviewees were asked (Q5 2012) to

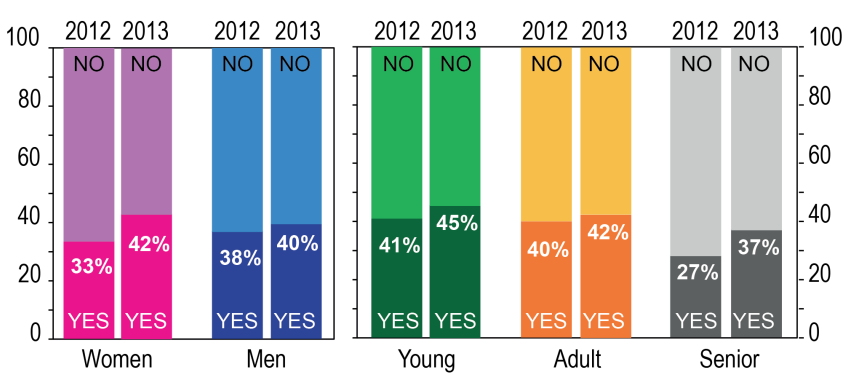

Figure 4. Bar charts show the percentage of "yes" and "no" answers to question 4 (Q4: Do you think that geo-hydrological events such as landslides and floods can be a real threat to your personal safety?), by sex and age, for the 2012 and 2013 surveys. Young (15 to 34 years old). Adult ( 35 to 54 years old). Senior (55 years old or older). See Table 1 for the question and the list of possible answers.

evaluate the total number of casualties (dead, injured and missing people) caused by landslides and floods in Italy in the previous five years, i.e. in the period from 2007 to 2011. Of all the interviewees, only $58 \%$ responded to this question; the remaining $42 \%$ said that they did not know. Analysis of the responses revealed that the interviewees overestimated largely the total number of casualties caused by landslides and floods, which in the five-year period 2007-2011 totaled 140. The majority of the respondents estimated the number of casualties as exceeding $400(21 \%)$, or as being in the range between 201 and 400 (12\%). 


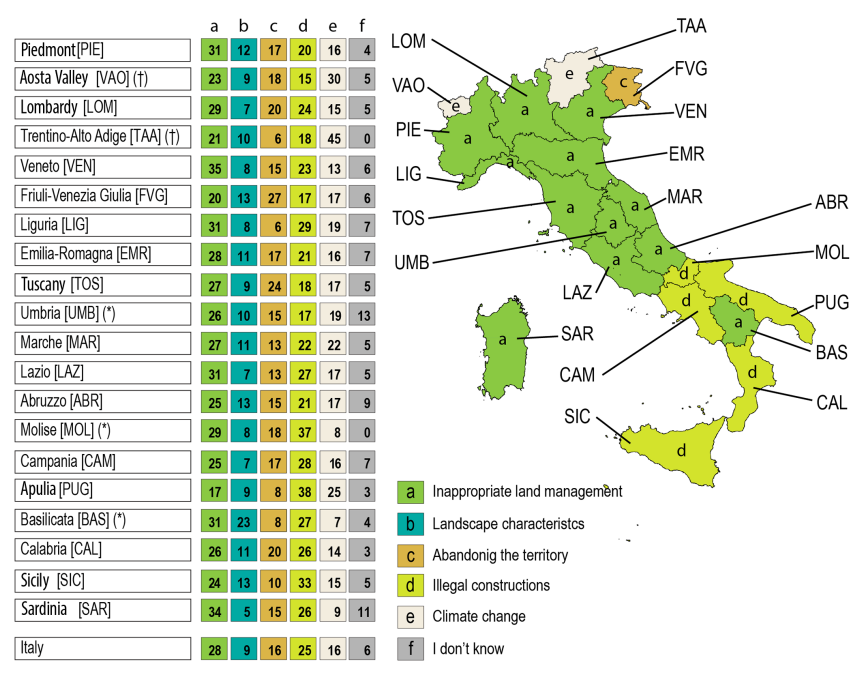

Figure 5. Answers to question 5 (Q5: In your opinion, which of the following factors have the most influence in the occurrence of landslides and floods?), by region and for Italy, for the 2013 survey. The table shows the percentage of the responses for the different considered factors. The map shows the factors with the largest percentage of responses, for each region. Colours in the map match colours in the table. Considered factors: (a) illegal construction ("abusive"), (b) inappropriate land management, (c) climate change, (d) landscape characteristics, (e) abandoning the territory, and (f) I do not know. A cross $(\dagger)$ marks regions where oversampling was performed to guarantee statistically significant results. An asterisk (*) marks regions for which the number of interviews was insufficient for obtaining statistically significant results. See Table 1 for the question and the list of possible answers.

Given the poor quantitative understating of the impact of landslides and floods on the population, we changed this question, and in the 2013 survey (Q52013 in Table 1), the interviewees were asked to select the factor(s) that they considered important for controlling or conditioning landslide and flood risk in Italy. More specifically, the interviewees were asked to select from a list of five possible factors affecting landslide and flood risk, including (a) inappropriate land management, (b) landscape characteristics, (c) abandoning of the territory, (d) illegal ("abusive") construction, and (e) climate change. In addition, the "do not know" answer was listed. Of the $94 \%$ of the interviewees that selected one or more of the proposed factors, $28 \%$ considered inappropriate land management to be the main cause of landslide and flood risk in Italy. This was followed by illegal construction $(25 \%)$, the abandonment of the territory $(16 \%)$, and climate change (16\%). Interestingly, only $9 \%$ of the interviewees considered landscape settings to be a factor contributing to landslide and flood risk. Inspection of Fig. 5 reveals that the responses given by the interviewees varied geographically. Most of the respondents in northern and central Italy considered inappropriate land management to be the primary cause of landslide and flood risk. In southern Italy, with the exception of Basilicata, "abusive" (illegal) construction was the single factor considered most important for landslide and flood risk. Indeed, many houses and buildings were constructed illegally (i.e. without proper permits) in southern Italy, increasing significantly the geo-hydrological risk to the population. Later, most of these houses and buildings became legal through specific legislation. Interestingly, in TrentinoAlto Adige (45\%) and the Valle d'Aosta (30\%), the respondents considered climate change (i.e. a largely natural cause) to be the main factor controlling landslide and flood risk. In these regions - and especially in Trentino-Alto Adige - land management is a priority, and considerable efforts are made and resources invested to mitigate geo-hydrological risks.

\section{Comparison of perceived and actual flood and landslide risk}

It is worth comparing the perception of flood and landslide risk in Italy probed by our two surveys to quantitative assessments of flood and landslide risk available at the synoptic scale in Italy (Guzzetti et al., 2005a; Salvati et al., 2010, 2012) (Table 3). We perform the comparison using maps and specifically designed cartograms. Cartograms are maps in which the sizes of the geographic subdivisions, such as the administrative regions used in our study, appear in proportion to a numerical attribute, e.g. the population (Dorling, 1996; Gastner and Newman, 2004). To address the size of the regions, we adopted the diffusion-based method proposed by Gastner and Newman (2004). This method adjusts the shape and size of a region using a numerical approach derived from the linear diffusion process of elementary physics. The individual regions are modified (stretched, enlarged, reduced) in such a way that the density of the population (or the density of any other numerical attribute) is the same for all the regions. Using this method, a region with a larger population is expanded, and a region with a smaller population is shrunk. The method produces "density-equalizing maps" (cartograms) that maintain the geographical relationships between the regions, facilitating their visual interpretation (Gastner and Newman, 2004).

For our comparison, we prepared two sets of maps and cartograms. Figure 6 shows the geographical distribution of the responses given to question 4 (Q4 in Table 1), in the 2013 survey. Maps A and B in Fig. 6 portray the (non-deformed) Italian regions coloured based on the percentage of the interviewees that considered landslides (A) and floods (B) a threat to their safety. Cartograms C (for landslides) and D (for floods) show the same information using the same legend and colour scheme used for maps A and B, but with the regions deformed based on the size of the population of each region (Table 2). As a result, the most populated regions (e.g. Lombardia, Lazio, and Campania) are larger, and the least populated regions (e.g. the Valle d'Aosta, Molise, Basilicata, and Umbria) are reduced. Cartograms $\mathrm{E}$ (for landslides) and $\mathrm{F}$ 

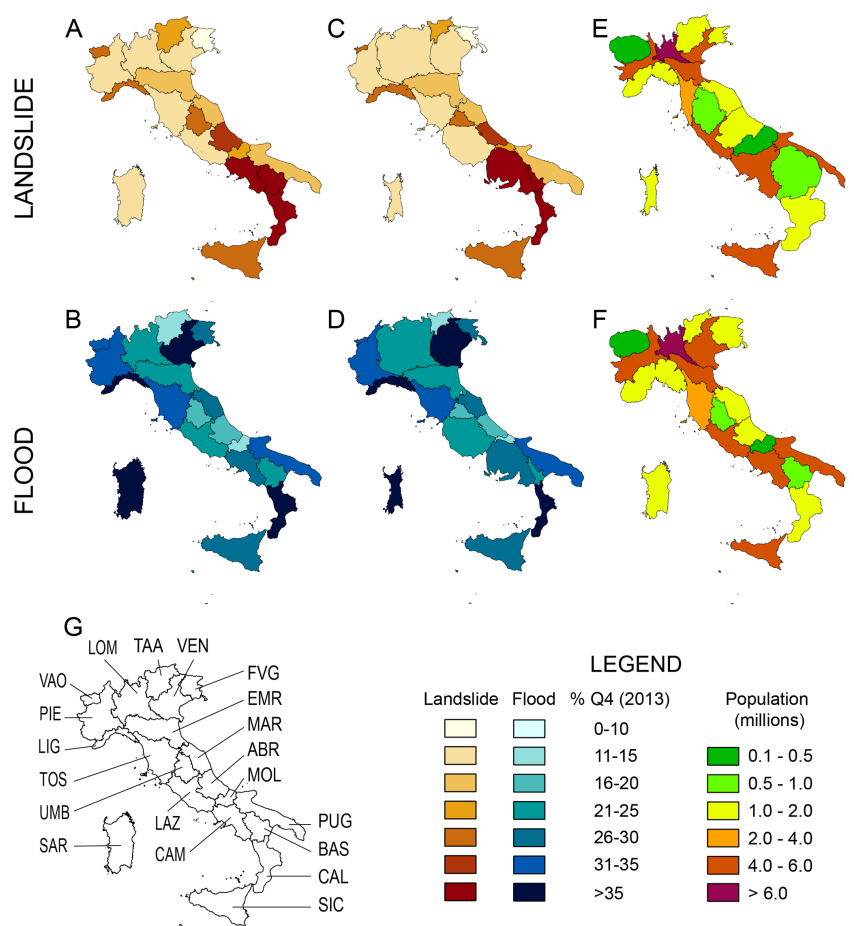

Figure 6. Geographical distribution of the responses to question 4 (Q4: Do you think that geo-hydrological events such as landslides and floods can be a real threat to your personal safety?) for landslides (shades of brown) and floods (shades of blue), in the 20 Italian regions. Shades of the colours portray the percentage of the respondents that felt threatened by landslides or floods, in each region (in 2013). Maps (a) and (b) show the true size and shape of the 20 Italian regions. Cartograms (c) and (d) prepared by deforming the regions based on the total population in each region (in 2013). Cartograms (e) and (f) prepared by deforming the regions based on the percentage of the respondents that felt threatened by landslides or floods (in 2013), and coloured by the size of the population in each region (in 2013). Map (g) gives the true size and shape of the 20 Italian regions, for reference.

(for floods) show the same information, but were obtained by changing the regions by the percentage of the respondents to $\mathrm{Q} 4$, and by colouring each region based on the size of the population in the region. In Fig. 7, we show the geographical distribution of landslide and flood risk in Italy measured by (i) the number of fatal landslide (A) and flood (B) events, (ii) the number of landslide (C) and flood (D) fatalities, and (iii) the average landslide (E) and flood (F) mortality in the 50year period 1964-2013. Mortality is the yearly average number of deaths per 100000 people (Guzzetti et al., 2005b). The cartograms in Fig. 7 were obtained by modifying the regions based on the size of the population. Collectively, the maps and the cartograms in Fig. 6 give a quantitative overview of the geographical distribution of the perception of landslide and flood risk in Italy, and the cartograms in Fig. 7 give the geographical distribution of different and complementary measures of landslide and flood risk to the population of Italy.

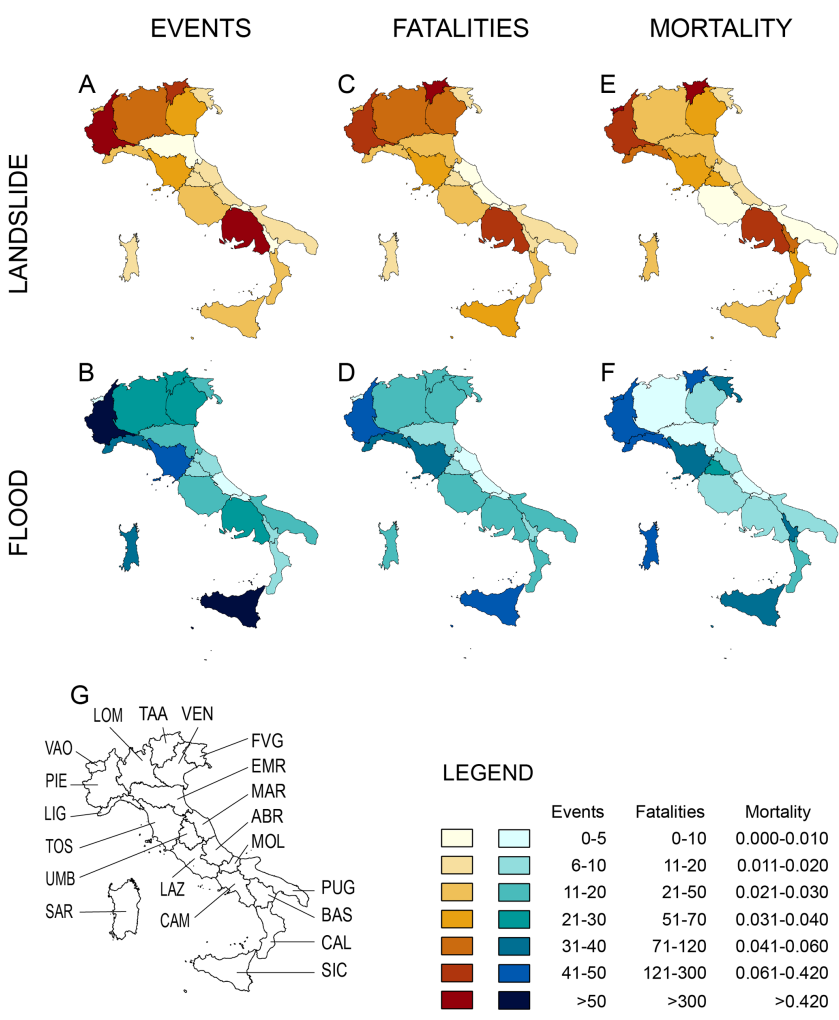

Figure 7. Cartograms showing landslide and flood risk in the 20 regions in Italy, measured by the number of fatal landslides (a) and flood (b) events, the number of landslide (c) and flood (d) fatalities, and the average landslide (e) and flood (f) mortality, in the 50-year period 1964-2013. See Table 3. Cartograms prepared by deforming the regions based on the size of the population in each region (in 2013). Map (g) gives the true size and shape of the 20 Italian regions, for reference.

In Italy, landslide risk to the population is largest in Campania, Piemonte, and Trentino-Alto Adige (Fig. 7, Table 3). Due to the lesser size of the population (Table 2), landslide mortality is also large in the Valle d'Aosta and significant in Basilicata. In Liguria, landslide mortality is significant, as a result of the number of fatalities compared to the size of the population. Visual inspection of Fig. 6 reveals that the perception of landslide risk, measured by the percentage of interviewees that considered landslides a threat to their safety (Q4 in Table 1), was largest in Campania, Basilicata and Calabria, and large in the Marche region. Thus, only in Campania is landslide risk high (in terms of mortality, number of fatalities, and number of fatal events; Fig. 7), and the perception of the risk was also high (Fig. 6). In Liguria, where landslide mortality is significant, the perception of the risk was also significant. In Piemonte and Trentino-Alto Adige, where landslide risk to the population is high (Fig. 7), the perception of the risk was moderate (Trentino-Alto Adige) or low (Piemonte). This can be a result of habituation and 
familiarity (Hazard and Seidel, 1993). Conversely, in Basilicata and Calabria, where the perception of the risk was very high, landslide risk to the population was moderate. We attribute the result to the several landslide events - fortunately without severe fatal consequences - that have occurred in the two regions in the last few years. In the regions where landslide risk is low, in terms of mortality and the number of fatalities (e.g. Molise, Puglia, and Lazio), the perception of the risk was intermediate, and not low. In Friuli-Venezia Giulia, where the proportion of the interviewees that considered landslides a personal threat was lowest (7\%, Fig. 7), landslide risk is moderately low.

Inspection of Fig. 7b, d, f and Table 3 reveals that the three metrics used to evaluate flood risk to the population of Italy are less consistent than for landslides (Fig. 7a, c, e). The number of fatal flood events is largest in Piemonte and Sicilia, is large in Toscana, and is smallest in Abruzzo and Molise (Fig. 7b). The number of flood fatalities is largest in Piemonte and Sicilia, large in Liguria and Toscana, and smallest in Marche, Abruzzo, and Molise (Fig. 7d). Flood mortality is largest in Piemonte, Liguria, Sardegna, the Valle d'Aosta, and Trentino-Alto Adige, and smallest in Abruzzo, Emilia-Romagna, Lombardia, and Molise (Fig. 7f). In the Valle d'Aosta and Trentino-Alto Adige, flood mortality is very large, due to the reduced size of the population in the two regions. The same occurs in Basilicata, where flood mortality is severe. High mortality in Liguria and Sardegna is due to the large number of fatalities compared to the size of the population. Inspection of Fig. 6 reveals that the perception of flood risk, measured by the percentage of the interviewees that considered floods a personal threat (Q4 in Table 1), was largest in Veneto, Liguria, Sardegna and Calabria, and large in Piemonte, the Valle d'Aosta, Toscana and Puglia. Thus, only in Liguria and Molise does the actual flood risk (large for Liguria and very low for Molise, Fig. 7) match the perception of the risk (Fig. 6). In the other regions, there exist more or less significant - differences between the actual flood risk (Fig. 7) and the perception of the threats (Fig. 6). We note that some of the regions where the perception of flood risk was highest (Campania, Liguria, Veneto) have been affected repeatedly by flood (and landslide) events in recent years.

We conclude that, with a few exceptions (e.g. Campania for landslides, and Liguria for floods), the perception of the threat posed by landslides and floods does not necessarily match the actual risk to the population of Italy, measured by landslide and flood mortality, and by the number of landslide and flood fatalities (Figs. 6, 7; Table 3).

\section{Discussion}

Analysis of the responses to our two surveys revealed that the population of Italy feels more exposed to technological (human-induced) than natural risks (Fig. 1). This is not new. McDaniels et al. (1995) and Slovic (1996) have ob- served that technological hazards are perceived to be more risky than natural hazards, despite the fact that the latter can cause severe damage. Our findings confirm this perception bias, which has multiple explanations. Sjöberg (1998) pointed out that natural risks are more sensorial than technological risks, which are more cognitive. Furthermore, natural hazards are often considered "acts of God", with no-one specific to blame, and with no way of preventing the hazards from happening (Wachinger and Renn, 2011). This can make natural hazards more frightening than technological hazards (Plapp and Werner, 2006).

A question in the surveys $(\mathrm{Q} 2$ in Table 1) measured the ability of individuals to evaluate the frequency, or the likelihood of occurrence, of the considered natural hazards in the general area where they lived. Collectively, the interviewees felt that in their area, earthquakes were the most likely risk, followed by floods, landslides, and volcanic activity. This was in spite of the fact that in Italy, geo-hydrological events (landslides and floods) are far more frequent than geophysical events (earthquakes and volcanic activity). Other studies have revealed the difficulty for individuals to make correct inferences from objective probabilistic information. Renn (2004) discussed factors that can alter the perception of individuals of the probability of natural risks, including the fact that (i) the events that come to mind to an individual are perceived to be more probable than the events that are less important to the individual, (ii) individuals tend to consider more likely those risks that they have experienced directly than those that they have not experienced, and (iii) individuals typically do not estimate probabilities using formal statistical reasoning. Trust also plays a role in the perception of natural risks, and chiefly when the knowledge or understanding of an individual of a specific risk is limited (Wachinger and Renn, 2011).

The third question (Q3 in Table 1) determined if the interviewees had (or did not have) direct experience or indirect knowledge of geo-hydrological hazards (i.e. landslides or floods). The majority of the interviewees had no direct experience or indirect knowledge of landslide or flood events in their area. As discussed before, this is in contrast to the abundance and frequency of landslides and floods in Italy (Guzzetti et al., 1994; Guzzetti and Tonelli, 2004). Lack of familiarity can have many causes, including a lack of interest in or low attention of individuals regarding hazardous natural events, which may depend on the lack of information and insufficient education on natural hazards and risks. In addition, in modern societies, people move frequently, and have fewer opportunities to interact with more experienced residents and to learn about the history and risks in the area where they live. Various studies support the hypothesis that experience influences the perception of natural hazards (Weinstein, 1989). Working in the Netherlands, Bezuyen et al. (1998) found that the public perception of flood risk changed after the 1993 destructive flooding. Siegrist and Gutscher (2006) studied the perception of flood risk in Switzerland, and found 
that in areas affected by historical floods, people were more aware of the risk. Individuals who remembered past flood events had a higher perception of the risk than individuals who could not remember - or had not experienced - adverse events. Our findings that the recent damaging events (e.g. the 2012 Emilia-Romagna earthquakes, or the repeated geo-hydrological events in Toscana, Lazio, and Umbria in 2012) increased risk perception confirm the previous results.

The fourth question (Q4 in Table 1) in our surveys determined the extent to which individuals consider geohydrological hazards a personal threat. In $2013,41 \%$ of the interviewees considered landslides and floods a direct threat. This is a high percentage, compared to the percentages obtained for the other questions (Fig. 4). Working in the USA, Haimes (2005) found that when people were asked about flood risk, they were more afraid of low-probability (less frequent) catastrophic events than of less severe, more frequent events. Scolobig et al. (2010), working in a small mountain area in the eastern Italian Alps, found that people considered geo-hydrological hazards less a threat to their personal safety than a threat to their homes, properties and villages, revealing a difference in the perception of individual and collective risk (Salvati et al., 2010, 2012), with a tendency to underestimate the former.

In the 2012 survey, the interviewees were asked to estimate the total number of casualties (dead, missing persons, injured people) caused by geo-hydrological hazards in Italy from 2007 to 2011. The majority of the respondents overestimated considerably the number of landslide and flood casualties, a measure of collective risk (Salvati et al., 2010, 2012). We explain the overestimation with the tendency of individuals to miscalculate the frequency and magnitude of severe events. This known bias was attributed by Sunstein and Zeckhauser (2011) to fear that amplifies the perception of risk.

In 2013, the interviewees were asked to identify the factors that they considered most important in conditioning geohydrological risks in Italy. Not surprisingly, the responses varied geographically (Fig. 5). We explain the geographical variations with (i) the observation that personal and public values and interests are guided by legislation and societal regulations (Wachinger and Renn, 2011), which vary regionally, and (ii) the different abilities of local and regional governments and public administrations to cope with geohydrological risks.

Finally, a number of studies have investigated risk perception as a function of sex and age. In many areas, the perception of natural risks was found to be independent of sex, but not of age. Miceli et al. (2008) studied flood risk in a mountainous area in the Valle d'Aosta, northern Italy, and found that younger people perceived flood risk to be higher than older people. This result is confirmed by our work (Fig. 4). The same study revealed that risk perception - and the related risk awareness - was highest immediately after a flood event, and decreased rapidly after the event (Miceli et al., 2008). This result outlines a general tendency to forget past (negative) experiences rapidly, and it is also confirmed by our work. The result is not new (Felgentreff, 2003), and must be considered when designing risk mitigation and adaptation strategies.

\section{Conclusions}

In 2012 and 2013, we conducted two surveys to investigate the perception of landslide and flood risk in Italy. The surveys were performed by interviewing through telephone calls approximately 3100 adults, using pre-defined questionnaires. Analysis of the responses showed that people in Italy feel more exposed to technological risks (environmental pollution and car accidents) than to natural risks. This was expected (Rohrmann and Renn, 2000). Of the natural risks, people in Italy feel more exposed to earthquakes, followed by floods, landslides, and volcanic eruptions. This is in general agreement with the societal risk levels posed by the different hazards (Guzzetti et al., 2005b; Salvati et al., 2012). Analysis of the temporal and the geographical variations of the responses indicated that the occurrence of recent events influences the perception of the risks, and that the perception of the risks decreased more rapidly for landslides and floods, and persisted longer for earthquakes. We attribute the difference to the different consequences and frequency of the risks (Slovic et al., 1986; Slovich, 1987; Hazard and Seidel, 1993).

Inappropriate land management was considered the main cause of landslide and flood risk in Italy, followed by illegal construction, abandonment of the territory, and climate change. However, the responses varied geographically. If in northern and central Italy, inappropriate land management was considered the primary cause of landslide and flood risk, in most of southern Italy, "abusive" (illegal construction) is the factor considered most important for controlling the risk.

Comparison of the perception of the risks with metrics of actual landslide and flood risk, including the number of fatal events, the number of fatalities, and mortality, revealed that the perception of the threat posed by geo-hydrological events does not effectively match the risk posed by landslides and floods to the population of Italy. This points to the need for renewed action to foster knowledge and improve the understanding that the population of Italy has of the geohydrological hazards and their risks (Morgan et al., 2001).

Acknowledgements. The surveys were conducted with the financial support of the Italian national Department of Civil Protection (DPC). CB and PG were supported by a grant of the DPC, and by a grant of the Fondazione Generali in the framework of a project to evaluate the costs of natural disasters in Italy. FF was supported by a grant of the Umbria region, under contract PoR-FESR 861, 2012. We are grateful to the editor, Bruce D. Malamud, to Peter T. Bobrowsky, and to a second anonymous reviewer for their constructive comments that helped us to improve the work. 
Edited by: B. D. Malamud

Reviewed by: P. Bobrowsky and one anonymous referee

\section{References}

Anzidei, M., Maramai, A., and Montone, P. (Eds.): The Emilia (northern Italy) seismic sequence of May-June, 2012: preliminary data and results, Ann. Geophys., 55, doi:10.4401/ag-6232, 2012.

Bezuyen, M. J., Van Duin, M. J., and Leenders, P.: Flood management in the Netherlands, Aust. J. Emerg. Manage., 132, 43-49, 1998

Boncio, P., Lavecchia, G., Milana, G., and Rozzi, B.: Seismogenesis in Central Apennines, Italy: an integrated analysis of minor earthquake sequences and structural data in the Amatrice-Campotosto area, Ann. Geophys. 47, 1723-1742, doi:10.4401/ag-3371, 2004.

Boschi, E., Ferrari, G., Gasperini, P., Guidoboni, E., Smirglio, G., and Valensise, G. (Eds.): Catalogo dei forti terremoti in Italia dal 41 a.C. al 1980, ING-SGA, Bologna, 1995.

Cruden, D. M. and Fell, R. (Eds.): Landslide Risk Assessment, Proceedings International Workshop on Landslide Risk Assessment, Honolulu, 19-21 February 1997, A.A. Balkema Publisher, Rotterdam, 1997.

Cruden, D. M. and Varnes, D. J.: Landslide Types and Processes; in Landslides: Investigation and Mitigation, in: U.S. Transportation Research Board, edited by: Turner, A. K. and Schuster, R. L., Special Report, no. 247, 36-75, 1996.

Cucci L., D’Addezio, G., Valensise, G., and Burrato, P.: Investigating seismogenic faults in central and southern Apennines (Italy): modeling of fault-related landscape features, Ann. Geophys., 39, 603-601, doi:10.4401/ag-3995, 1996.

Davy, B.: Fairness as compassion: towards a less unfair facility siting policy, Risk: Health, Safe. Environ., 7, 99-108, 1996.

Directive 2007/60/EC of the European Parliament and of the Council of 23 October 2007 on the assessment and management of flood risks, available at: http://eur-lex.europa.eu/LexUriServ/ LexUriServ.do?uri=OJ:L:2007:288:0027:0034:EN:PDF (last access: 1 July 2014), 2007.

Douglas, M. and Wildavsky, A. B.: Risk and Culture: An essay on the selection of technical and environmental dangers, University of California Press, Berkeley, 1983.

Dorling, D.: Area Cartograms: Their Use and Creation. Concepts and Techniques in Modern Geography, 59, Geo Books, 69 pp., 1996.

Felgentreff, C.: Post-disaster situations as windows of opportunity? Post-flood perception and changes in the German Odra River Region after 1997 flood, Die Erbe, 134, 163-180, 2003.

Fell, R. and Hartford, D.: Landslide risk management, in: Landslide Risk Assessment, edited by: Cruden, D. M. and Fell, R., A.A. Balkema Publisher, Rotterdam, 51-109, 1997.

Fischhoff, B., Slovic, P., and Lichtenstein, S.: How Safe is Safe Enough? A Psychometric Study of Attitudes Towards Technological Risks and Benefits, Pol. Sci., 9, 127-152, 1978.

Fromm, J.: Risk Denial and Neglect: Studies in Risk Perception, Stockholm School of Economics, 2005.
Gastner, M. T. and Newman, M. E. J.: Diffusion-Based Method for Producing Density-Equalizing Maps, Proc. Natl. Acad. Scie., 101, 7499-7504, doi:10.1073/pnas.0400280101, 2004.

Guzzetti, F.: Landslide Fatalities and the Evaluation of Landslide Risk in Italy, Eng. Geol., 58, 89-107, doi:10.1016/S00137952(00)00047-8, 2000.

Guzzetti, F. and Tonelli, G.: Information system on hydrological and geomorphological catastrophes in Italy (SICI): a tool for managing landslide and flood hazards, Nat. Hazards Earth Syst. Sci., 4, 213-232, doi:10.5194/nhess-4-213-2004, 2004.

Guzzetti, F., Cardinali, M., and Reichenbach, P.: The AVI Project: A bibliographical and archive inventory of landslides and floods in Italy, Environ. Manage., 18, 623-633, 1994.

Guzzetti, F., Stark, C. P., and Salvati, P.: Evaluation of flood and landslide risk to the population of Italy, Environ. Manage., 36, 15-36, doi:10.1007/s00267-003-0257-1, 2005a.

Guzzetti, F., Salvati, P., and Stark, C. P.: Evaluation of risk to the population posed by natural hazards in Italy, in: Landslide Risk Management, edited by: Hungr, O., Fell, R., Couture, R., and Eberhardt, E., Taylor \& Francis Group, London, ISBN 041538043X, 381-389, 2005b.

Haimes, Y. Y.: Risk of extreme events and the fallacy of expected value, in: Risk Modeling, Assessment, and Management, John Wiley \& Sons, doi:10.1002/0471723908.ch8, 2005.

Hazard, B. and Seidel, G.: Informationsbedingte und psychosoziale Ursachen für die Angst vor Gesundheitsschäden durch Radon, in: Umweltbelastungen und Ängste, edited by: Aurand, K., Hazard, B., and Tretter, F., Westdeutscher Verlag, Opladen, 113-132, 1993.

Hungr, O., Leroueil, S., and Picarelli, L.: The Varnes classification of landslide types, an update, Landslides, 11, 167-194, doi:10.1007/s10346-013-0436-y, 2013.

Jonkman, S. N., van Gelder, P. H. A. J. M., and Vrijling, J. $\mathrm{K}$.: An overview of quantitative risk measures for loss of life and economic damage, J. Hazardous Material, A99, 1-30, doi:10.1016/S0304-3894(02)00283-2, 2003.

Jungermann, H. and Slovic, P.: Characteristics of individual risk perception, in: Risk - a construct, edited by: Bayerische-Reuch, Knesebeck, Muenchen, 58-102, 1993.

Kasperson, R. E., Renn, O., Slovic, P., Brown, H. S., Emel, J., Goble, R., Kasperson, J. X., and Ratick, S.: The social amplification of risk: a conceptual framework, Risk Anal., 8, 177-187, doi:10.1111/j.1539-6924.1988.tb01168.x, 1988.

Ketola, E. and Klockars, M.: Computer-assisted telephone interview (CATI) in primary care, Family Practice, 16, 179-183, doi:10.1093/fampra/16.2.179, 1999.

Latter, J. H.: Natural disasters, Adv. Sci., 25, 362-380, 1969.

Linnerooth-Bayer, J. and Fitzgerald, K.B.: Conflicting views on fair siting processes, Risk: Health, Safe. Environ., 7, 119-134, 1996.

Marris, C., Langford, I., and O'Riordan, T.: A quantitative test of the Cultural Theiìory of Risk perception; comparison with the psychometric paradigm, Risk Anal., 18, 635-647, 1998.

McDaniels, T., Axelrod, L., and Slovic, P.: Characterizing perception of ecological risk, Risk Anal., 15, 575-590, 1995.

Miceli, R., Sotgiu, I., and Settanni, M.: Disaster preparedness and perception of flood risk: a study in an alpine valley in Italy, J. Environ. Psychol., 28, 164-173, doi:10.1016/j.jenvp.2007.10.006, 2008. 
Morgan, G. C.: A regulatory perspective on slope hazards and associated risks to LIFE., in: Landslide Risk Assessment, edited by: Cruden, D. M. and Fell R., 285-295, Balkema, Rotterdam, 1997.

Morgan, M. G., Fishhoff, B., Bostrom, A., and Atman, C. J.: Risk communication: a mental models approach, Cambridge University Press, Cambridge, 2001.

Oltedal, S., Moen, B., Klempe, H., and Rundmo, T.: Explain risk perception. An evaluation of cultural theory, Rotunde Publikasjoner, Trondheim, 2004.

Plapp, T. and Werner, U.: Understanding risk perception from natural hazards: Examples from Germany, in: Risk 21 Coping with risks due to natural hazards in the 21th century, edited by: Ammann, W. J., Dannenmann, S., and Vulliet, L., Taylor \& Francis Group, London, 101-108, 2006.

Renn, O.: Concepts of risk: a classification, in: Social theories of risk, edited by: Krimsky, S. and Golding, D., Westport, CT, Praeger, London, 53-79, 1992.

Renn, O., Burns, W. J., Kasperson, J. X., Kasperson, R. E., and Slovic, P.: The social amplification of risk: theoretical foundations and empirical applications, J. Social Issues, 48, 137-160, doi:10.1111/j.1540-4560.1992.tb01949.x, 1992.

Renn, O.: Perception of risks, The Geneva Papers on Risk and Insurance, 29, 102-114, 2004.

Rippl, S.: Cultural Theory and Risk Perception: a Proposal for a Better Measurement, J. Risk Res., 5, 147-165, doi:10.1080/13669870110042598, 2002.

Rohrmann, B. and Renn, O.: Risk perception research - An introduction, in: Cross-cultural risk perception research, edited by: Renn, O. and Rohrmann, B., Kluwer, Dordrecht, 2000.

Salvati, P., Bianchi, C., Rossi, M., and Guzzetti F.: Flood Risk in Italy, in: Changes of flood risk in Europe, edited by: Kundzewicz, Z., IAHS Special Publication 10, IAHS Press, UK, 277-292, available at: http://www.iahs.info/bluebooks/SP010.pdf, 2012.

Salvati, P., Bianchi, C., Rossi, M., and Guzzetti, F.: Societal landslide and flood risk in Italy, Nat. Hazards Earth Syst. Sci., 10, 465-483, doi:10.5194/nhess-10-465-2010, 2010.

Schmidt, M.: Investigating risk perception: a short introduction, in: Loss of agro-biodiversity in Vavilov centers, with a special focus of genetically modified organisms (GMOs), edited by: Schmidt, M., Ph.D. Thesis, Vienna, 2004.
Scolobig, A., De Marchi, B., Pellizzoni, L., and Bianchizza, C.: Alpine hazards, in: CapHaz-Net WP3 Report on risk perception, 2010.

Siegrist, M. and Gutscher, H.: Flooding risk: a comparison of lay people's perception and expert's assessments in Switzerland, Risk Anal., 26, 971-979, doi:10.1111/j.15396924.2006.00792.x, 2006.

Sjöberg, L.: Factors in Risk Perception, Risk Anal., 20, 1-11, doi:10.1111/0272-4332.00001, 2000.

Slejko, D., Peruzza, L., and Rebez, A.: Seismic hazard maps of Italy, Ann. Geophys., 41, doi:10.4401/ag-4327, 1998.

Slovic, P.: Perception of Risk, Science, 236, 280-285, doi:10.1126/science.3563507, 1987.

Slovic, P., Fischhoff, B., and Lichtenstein, S.: Why Study Risk Perception?, Risk Anal., 2, 83-93, doi:10.1111/j.15396924.1982.tb01369.x, 1982.

Slovic, P., Fischhoff, B., and Liechtenstein, S.: The psychometric study of risk perceptions, in: Risk evaluation and management, edited by: Covello, V. T., Menkes, J., and Mumpower, J., Plenum Press, 3-24, 1986.

Starr, C.: Social benefit versus technological risk, Science, 165, 1232-1238, 1969.

Sunstein, C. R.: A note on "voluntary" versus "involuntary" risks, Duke Environ. Law Pol. Forum, 8, 173-180, 1997.

Sunstein, C. R. and Zeckhauser, R.: Overreaction to fearsome risk, Environ. Resour. Econom., 48, 435-449, doi:10.1007/s10640010-9449-3, 2011.

Tansey, J. and O'Riordan, T.: Cultural theory and risk: a review, Health, Risk Soc., 1, 71-90, 1999.

Wachinger, G. and Renn, O.: Risk perception and natural hazard, CapHaz-Net WP3 Report on risk perception, 2011.

WBGU: World in Transition. Strategies for global environmental risks. Annual report of the German Advisory council on global change, Springer, 1998.

Weistein, N. D.: Unrealistic optimism about future life events, J. Personal. Social Psychol., 39, 806-820, doi:10.1037/00223514.39.5.806, 1980.

Weistein, N. D.: Effect of personal experience on self-protective behaviour, Psychological Bull., 105, 31-50, doi:10.1037/00332909.105.1.31, 1989.

Wildavsky, A. and Dake, K.: Theories of risk perception: who fears what and why?, Daedalus, 4, 41-60, 1990. 